\title{
Statystyczna ocena wpływu parametrów napawania SSA na geometrię napoin
}

\author{
Statistic determination of self-shielded arc surfacing \\ parameters influence on the padding welds geometry
}

\section{Streszczenie}

W artykule omówiono problem określenia parametrów istotnych dla napawania drutem rdzeniowym samoosłonowym. Metoda SSA jest jedną ze spawalniczych metod, która daje duże możliwości w wytwarzaniu napoin o zróżnicowanym składzie chemicznym i dobrej jakości. Istotne jest określenie, które z parametrów napawania mają znaczący wpływ na właściwości napoiny. Zastosowanie planu Placketta-Burmana umożliwiło statystyczną ocenę istotności wpływu wybranych parametrów napawania na geometrię napoiny.

\section{Wstęp}

Technologie napawania dzieli się na napawanie prewencyjne (technologiczne) i regeneracyjne. Napawanie regeneracyjne jest ekonomicznym sposobem przywracania cech użytkowych, a dzięki zastosowaniu materiałów warstwowych, w wyniku napawania technologicznego uzyskuje się optymalizację właściwości warstw kontaktowych $[1 \div 5]$. Metodą najmniej znaną, ale rokującą uzyskanie dobrych napoin, jest napawanie łukowe drutem rdzeniowym samoosłonowym - SSA (Self Shielded Arc Surfacing). Łączy ono cechy napawania łukowego ręcznego i napawania elektrodą topliwą w osłonie gazowej. Proces napawania drutami rdzeniowymi samoosłonowymi SSA łączy cechy napawania drutami rdzeniowymi w osłonie gazowej i napawania ręcznego elektrodami otulonymi. Sam proces napawania $z$ technologicznego punktu widzenia przebiega tak samo jak napawanie drutem proszkowym w osłonie gazowej. W przypadku napawania SSA drutem samoosłonowym prostszą konstrukcję mają

Dr inż. Robert Bęczkowski, dr inż. Marek Gucwa - Politechnika Częstochowska.

\section{Abstract}

In this work problem of determining of parameters for surfacing by using self-shielded arc is concerned. Self shielded arc surfacing (SSA) is one of the welding methods that gives big opportunities for producing cladding with wide range of chemical composition and good quality. The problem is to determine which parameters have the significant influence for producing cladding with defined properties. Using Plackett-Burman's design gives opportunities to statistic evaluation of significant parameters on cladding properties especially its geometry.

uchwyty spawalnicze, ponieważ niepotrzebny wtedy jest system osłony gazowej łuku. Sam proces napawania prowadzony jest głównie z zastosowaniem prądu stałego z biegunowością dodatnią, stosowany jest również prąd pulsujący. Możliwe jest również napawanie prądem stałym z biegunowością ujemną lub prądem przemiennym. Zastosowanie prądu stałego o biegunowości dodatniej podyktowane jest najlepszą stabilnością jarzenia się łuku elektrycznego i małym rozpryskiem. Odbywa się to kosztem większej głębokości wtopienia i mniejszej wydajności napawania, niż przy zastosowaniu biegunowości ujemnej, przy której łuk elektryczny jest dużo mniej stabilny.

Do podstawowych parametrów napawania SSA zaliczane są: rodzaj i natężenie prądu napawania, napięcie łuku, prędkość podawania drutu proszkowego, prędkość napawania, długość wystającego odcinka drutu proszkowego, kąt pochylenia drutu proszkowego względem napawanego przedmiotu, rodzaj i średnica drutu proszkowego.

Określenie stopnia istotności wpływu danego parametru napawania na wynik końcowy przy znacznej liczbie parametrów oddziałujących jednocześnie jest kłopotliwe i czasochłonne. Celowe jest więc opracowanie planu badań ograniczającego do niezbędnego minimum liczbę doświadczeń, która pozwala na otrzymanie 
wiarygodnych wyników. Takie możliwości daje planowanie doświadczeń na podstawie programów statystycznych, które pozwalają zoptymalizować liczbę doświadczeń i pomagają w statystycznym opracowaniu otrzymanych wyników. Chętnie wykorzystywane do

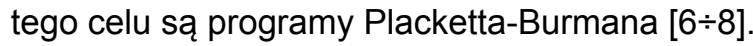

\section{Planowanie eksperymentu}

W badaniach eksperymentalnych wykorzystano planowanie doświadczenia wg programów Placketta-Burmana. Programy te budowane są na podstawie macierzy Hadamarda, które są macierzami kwadratowymi rzędu $n$ spełniającymi zależność [9]:

$$
\mathrm{H}^{\top} \mathrm{H}=n \mathrm{E}_{n}
$$

gdzie: $\mathrm{E}_{n}$ - macierz jednostkowa rzędu $n, \mathrm{H}^{\top}$ - transpozycja macierzy $\mathrm{H}$. runki:

Plany Placketta-Burmana muszą spełniać dwa wa-

- liczba doświadczeń musi być równa krotności 4: $\mathrm{N}=4 \mathrm{k}$, gdzie $k$ - liczba całkowita,

- liczba doświadczeń jest ograniczona do 100 i różna od 92.

Dzięki zastosowaniu programów Plakcetta-Burmana można oceniać istotność wpływu $4 k-1$ czynników badanych na czynnik wynikowy. Oznacza to, że dla np. 8 doświadczeń można określić wpływ maksymalnie 7 czynników wejściowych. Należy przy tym uwzględnić zmienne fikcyjne, które wykorzystuje się do obliczania wariancji błędu doświadczenia. Położenie zmiennych fikcyjnych jest wyznaczane losowo na podstawie tablic liczb losowych.

\section{Wnioskowanie statystyczne}

Tablica planu Placketta-Burmana zawiera dodatkowo układ centralny, który pozwala na zbadanie liniowości funkcji. Jeśli wielkości z układów spoza centrum różnią się istotnie od średniej układu centrum, może to świadczyć o nieliniowości zależności parametru wyjścia.
Wnioskowanie o podobieństwie 2 populacji odbywa się na podstawie parametrycznych testów istotności.

Test dla 2 średnich zakłada, że są normalne, tzn. $\mathrm{N}_{1}\left(\overline{\mathrm{x}}_{1}, \sigma_{1}\right), \mathrm{N}_{2}\left(\overline{\mathrm{x}}_{2}, \sigma_{2}\right)$ oraz $\sigma_{1}=\sigma_{2}$. Na podstawie odpowiednio licznych prób $n_{1}$ i $n_{2}$ weryfikowana jest hipoteza $\mathrm{H}_{0}=\overline{\mathrm{x}}_{1}=\overline{\mathrm{x}}_{2}$ oraz alternatywna hipoteza $\mathrm{H}_{1}=\overline{\mathrm{x}}_{1} \neq \overline{\mathrm{x}}_{2}$. W tym celu oblicza się wartości średnie $\bar{x}_{1}$ i $\bar{x}$

$$
\bar{x}=\frac{1}{n} \sum_{i=1}^{n} x_{i}
$$

wariancje $\bar{S}_{1}^{2}$ i $\bar{S}_{2}^{2}$

$$
S^{2}=\frac{1}{n} \sum\left(\bar{x}-x_{i}\right)^{2}
$$

a następnie wartości rozkładu t-Studenta

$$
t=\frac{\bar{x}_{1}-\bar{x}_{2}}{\sqrt{\frac{n_{1} S_{1}^{2}+n_{2} S_{2}^{2}}{n_{1}+n_{2}-2}\left(\frac{1}{n_{1}}+\frac{1}{n_{2}}\right)}}
$$

\section{Przeprowadzenie eksperymentu}

Napoiny zostały wykonane na zautomatyzowanym stanowisku do napawania. Zastosowano napawanie jednowarstwowe ściegiem zakosowym z parametrami przedstawionymi w tablicy I. Tablica ta jest stworzona wg programu Placketta-Burmana. W macierzy tej są kolumny zawierające zmienne rzeczywiste oraz kolumny zawierające zmienne fikcyjne. Miejsca zmiennych fikcyjnych i rzeczywistych ustalone zostały przy wykorzystaniu tablic liczb losowych, zmienne rzeczywiste są oznaczone przez X2, X3, X4, X6.

Oprócz podanych w tablicy I zmiennych rzeczywistych zmianom podlegały następujące parametry napawania: szerokość zakosów $(25 \div 45 \mathrm{~mm})$, prędkość podawania drutu $(5,3 \div 6,3 \mathrm{~m} / \mathrm{min})$, prędkość oscylacji $(1,7 \div 2,8 \mathrm{~m} / \mathrm{min})$. Wielkości te nie były przedmiotem analiz.

Wielkości wyjściowe realizowanego planu badań to: $\mathrm{B}_{\mathrm{n}}$ - szerokość napoiny, $\mathrm{mm}$

$\mathrm{H}_{\mathrm{n}}$ - wysokość napoiny, mm

$\mathrm{H}_{w}^{\mathrm{n}}$ - głębkość wtopienia, mm

$\mathrm{U}_{\mathrm{mr}}^{\mathrm{w}}$ - udział materiału rodzimego w napoinie, \%.

Wykorzystując zależności pomiędzy wielko-

\begin{tabular}{|c|c|c|c|c|c|c|c|}
\hline & $\mathrm{X} 1$ & $\mathrm{X} 2$ & X3 & X4 & $\times 5$ & $\mathrm{X} 6$ & $\times 7$ \\
\hline Nr próbki & $\begin{array}{c}\text { Szerokość } \\
\text { zakosów, mm }\end{array}$ & $\begin{array}{l}\text { Prędkość napa- } \\
\text { wania, } \mathrm{mm} / \mathrm{min}\end{array}$ & $\begin{array}{c}\text { Odbiór ciepła, } \\
\qquad \mathrm{W} / \mathrm{m} * \mathrm{~K}\end{array}$ & Moc, W & $\begin{array}{c}\text { Prędkość podawania } \\
\text { drutu, } \mathrm{m} / \mathrm{min}\end{array}$ & $\begin{array}{c}\text { Długość wystającego } \\
\text { odcinka drutu, mm }\end{array}$ & $\begin{array}{l}\text { Prędkość oscyla- } \\
\text { cji, m/min }\end{array}$ \\
\hline 1 & 1 & 130 & 0,15 & 12915 & -1 & 40 & 1 \\
\hline 2 & 1 & 190 & 0,15 & 10045 & 1 & 20 & 1 \\
\hline 3 & 1 & 190 & 4,3 & 10045 & -1 & 40 & -1 \\
\hline 4 & -1 & 190 & 4,3 & 12915 & -1 & 20 & 1 \\
\hline 5 & 1 & 130 & 4,3 & 12915 & 1 & 20 & -1 \\
\hline 6 & -1 & 190 & 0,15 & 12915 & 1 & 40 & -1 \\
\hline 7 & -1 & 130 & 4,3 & 10045 & 1 & 40 & 1 \\
\hline 8 & -1 & 130 & 0,15 & 10045 & -1 & 20 & -1 \\
\hline 9 & 0 & 160 & 2,15 & 11480 & 0 & 30 & 0 \\
\hline
\end{tabular}
ściami wejściowymi niezależnymi a wielkościami

Tablica I. Parametry procesu

Table I. Process parameters 
wejściowymi zależnymi, opracowano model matematyczny procesu napawania. Wielkościami wejściowymi są zmienne niezależne w postaci parametrów technologicznych:

$V_{\text {nap }}$ - prędkość napawania $\mathrm{mm} / \mathrm{min}$,

$\lambda^{\text {nap }}$ - współczynnik przewodzenia ciepła

$P-$ moc W,

$L_{e}-$ długość wystającego odcinka drutu $\mathrm{mm}$.

Jako zmienne zależne przyjęto: szerokość zakosów, prędkość podawania drutu oraz prędkość oscylacji. Przyjęto również następującą postać równania regresji:

$$
y=B_{0}+B_{1 \times 1}+B_{2 \times 2}+B_{3 \times 3}+B_{4 \times 4}
$$

Wielkościom określonym w równaniu (5) zostały przyporządkowane parametry z tablicy I. Równanie regresji ma wówczas postać:

$$
y=B_{0}+B_{1} V_{\text {nap }}+B_{2} \lambda+B_{3} P+B_{4} L_{e}
$$

\section{Wyniki eksperymentu}

$\mathrm{Na}$ rysunku przedstawiono widok przekroju poprzecznego napoin wykonanych w ramach eksperymentu i poddanych badaniom geometrii.

W celu określenia wpływu parametrów napawania na określoną wielkość wyjściową - w tym przypadku $H_{n}$ - wysokość napoiny, wykonano analizę statystyczną

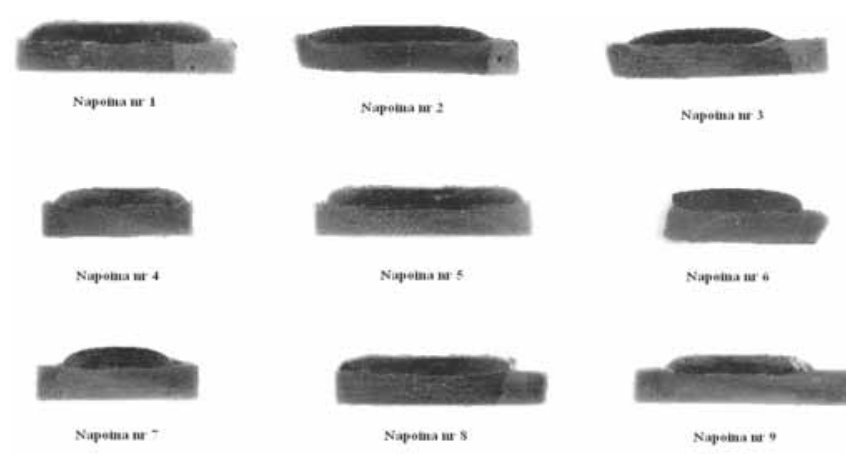

Rys. 1. Przekrój poprzeczny badanych napoin

Fig. 1. The cross-sections of tested padding welds

badanej zmiennej. Analiza ta pozwala określić funkcję rozkładu zmiennej. Wyniki pomiarów oraz analizy statystycznej dla badanej wielkości przedstawiono w tablicy II.

Wykorzystując wzory $(2 \div 6)$, potwierdzono liniowość rozkładu badanej wielkości oraz przy przyjętych założeniach poziomu istotności $\alpha=0,1$ i na podstawie dostępnych danych określono równanie regresji w postaci:

$$
y=4,316-0,808 x_{1}
$$

\section{Głębokość wtopienia}

Kolejną analizowaną wielkością jest $H_{w}$ - głębokość wtopienia. Analiza przebiegała podobnie jak

\begin{tabular}{|c|c|c|c|c|c|c|c|c|c|}
\hline \multirow{2}{*}{ Numer pomiaru } & \multicolumn{9}{|c|}{ Numer próbki } \\
\hline & 1 & 2 & 3 & 4 & 5 & 6 & 7 & 8 & 9 \\
\hline 1 & 4,45 & 3,14 & 3,35 & 3,88 & 4,52 & 4,91 & 5,12 & 4,6 & 4,21 \\
\hline 2 & 4,86 & 3,59 & 3,62 & 4,12 & 4,33 & 5,07 & 5,05 & 4,75 & 4,17 \\
\hline 3 & 4,56 & 3,2 & 3,34 & 4,04 & 4,46 & 4,86 & 5,18 & 4,93 & 4,23 \\
\hline Średnia & 4,62 & 3,31 & 3,44 & 4,01 & 4,44 & 4,95 & 5,12 & 4,76 & 4,20 \\
\hline Odchylenie standardowe & 0,212 & 0,244 & 0,159 & 0,122 & 0,097 & 0,110 & 0,065 & 0,165 & 0,031 \\
\hline Wariancja & 0,045 & 0,060 & 0,025 & 0,015 & 0,009 & 0,012 & 0,004 & 0,027 & 0,001 \\
\hline Liczebność & 3 & 3 & 3 & 3 & 3 & 3 & 3 & 3 & 3 \\
\hline Wartość min & 4,45 & 3,14 & 3,34 & 3,88 & 4,33 & 4,86 & 5,05 & 4,6 & 4,17 \\
\hline Wartość max & 4,86 & 3,59 & 3,62 & 4,12 & 4,52 & 5,07 & 5,18 & 4,93 & 4,23 \\
\hline Rozstęp & 0,41 & 0,45 & 0,28 & 0,24 & 0,19 & 0,21 & 0,13 & 0,33 & 0,06 \\
\hline
\end{tabular}

Tablica II. Wyniki pomiarów i analizy wysokości napoiny $H_{n}$

Table II. The results of tests and analysis of padding weld high $H_{n}$

\begin{tabular}{|c|c|c|c|c|c|c|c|c|c|}
\hline \multirow{2}{*}{ Nr pomiaru } & \multicolumn{9}{|c|}{ Nr próbki } \\
\hline & 1 & 2 & 3 & 4 & 5 & 6 & 7 & 8 & 9 \\
\hline 1 & 2,1 & 1,8 & 0,9 & 1,8 & 2,1 & 1,9 & 1,1 & 1,4 & 1,1 \\
\hline 2 & 1,76 & 1,45 & 1,1 & 1,35 & 2,15 & 1,46 & 1,26 & 1,72 & 1,32 \\
\hline 3 & 1,83 & 2,06 & 1,24 & 1,76 & 2,02 & 1,37 & 0,83 & 1,56 & 1,18 \\
\hline Średnia & 1,90 & 1,77 & 1,08 & 1,64 & 2,09 & 1,58 & 1,06 & 1,56 & 1,20 \\
\hline Odchylenie standardowe & 0,180 & 0,306 & 0,171 & 0,249 & 0,066 & 0,284 & 0,217 & 0,160 & 0,111 \\
\hline Wariancja & 0,032 & 0,094 & 0,029 & 0,062 & 0,004 & 0,080 & 0,047 & 0,026 & 0,012 \\
\hline Liczebność & 3 & 3 & 3 & 3 & 3 & 3 & 3 & 3 & 3 \\
\hline Wartość min & 1,76 & 1,45 & 0,9 & 1,35 & 2,02 & 1,37 & 0,83 & 1,4 & 1,1 \\
\hline Wartość max & 2,1 & 2,06 & 1,24 & 1,8 & 2,15 & 1,9 & 1,26 & 1,72 & 1,32 \\
\hline Rozstęp & 0,34 & 0,61 & 0,34 & 0,45 & 0,13 & 0,53 & 0,43 & 0,32 & 0,22 \\
\hline
\end{tabular}

Tablica III. Wyniki pomiarów i analizy głębokości wtopienia napoiny $H_{w}$

Table III. The results of tests and analysis of fusion depth padding weld $H_{w}$ 
w przypadku wysokości napoiny. Wyniki pomiarów i obliczeń zostały zamieszczone w tablicy III.

Przy przyjętych założeniach poziomu istotności $\alpha=0,1$ i na podstawie dostępnych danych określono równanie regresji w postaci:

$$
y=1,543-0,238 x_{2}+0,428 x_{3}-0,364 x_{4}
$$

\section{Udział materiału rodzimego w napoinie}

Kolejną wielkością poddaną badaniom statystycznym był $U_{m r}-$ udział materiału rodzimego $w$ napoinie (tabl. IV). Analizę wykonano zgodnie ze schematem, jaki został zastosowany przy analizie poprzednich wielkości.
Przy przyjętych założeniach poziomu istotności $\alpha=0,1$ i na podstawie dostępnych danych określono równanie regresji w postaci:

$$
y=25,630+6,207 x_{1}-3,473 x_{4}
$$

W tablicy $V$ zebrano równania regresji dla 3 badanych wielkość charakteryzujących napoinę.

Tabela V. Równania regresji

Table V. Regression equations

\begin{tabular}{|l|l|}
\hline \multicolumn{1}{|c|}{ Określana wielkość } & \multicolumn{1}{|c|}{ Postać równania regresji } \\
\hline Wysokość napoiny & $y=4,316-0,808 x_{1}$ \\
\hline Głębokość wtopienia & $y=1,543-0,238 x_{2}+0,428 x_{3}-0,364 x_{4}$ \\
\hline $\begin{array}{l}\text { Udział materiału } \\
\text { rodzimego w napoinie }\end{array}$ & $y=25,630+6,207 x_{1}-3,473 x_{4}$ \\
\hline $\begin{array}{l}\text { gdzie: } x_{1}-\text { prędkość napawania, } x_{2}-\text { odbiór ciepła, } x_{3}-\text { moc łuku, } \\
\mathrm{x}_{4}-\text { długość wystającego odcinka drutu }\end{array}$ \\
\hline
\end{tabular}

Tablica IV. Wyniki pomiarów i analizy udziału materiału rodzimego w napoinie $U_{m r}$

Table IV. The results of tests and analysis of base material in the padding weld ratio $U_{m r}$

\begin{tabular}{|c|c|c|c|c|c|c|c|c|c|}
\hline \multirow{2}{*}{ Nr pomiaru } & \multicolumn{9}{|c|}{ Nr próbki } \\
\cline { 2 - 10 } & 1 & 2 & 3 & 4 & 5 & 6 & 7 & 8 & 9 \\
\hline 1 & 23,94 & 33,47 & 24,95 & 32,1 & 21,43 & 25,64 & 22,66 & 20,54 & 27,98 \\
\hline 2 & 22,1 & 32,62 & 23,27 & 30,43 & 24,36 & 25,15 & 22,17 & 21,84 & 26,86 \\
\hline 3 & 23,5 & 33,93 & 24,32 & 31,78 & 22,14 & 24,49 & 21,88 & 21,11 & 27,34 \\
\hline Średnia & 23,18 & 33,34 & 24,18 & 31,44 & 22,64 & 25,09 & 22,24 & 21,16 & 27,39 \\
\hline Odchylenie standardowe & 0,961 & 0,665 & 0,849 & 0,886 & 1,528 & 0,577 & 0,394 & 0,652 & 0,562 \\
\hline Wariancja & 0,923 & 0,442 & 0,720 & 0,786 & 2,336 & 0,333 & 0,155 & 0,425 & 0,316 \\
\hline Liczebnośćn & 3 & 3 & 3 & 3 & 3 & 3 & 3 & 3 & 3 \\
\hline Wartość min & 22,1 & 32,62 & 23,27 & 30,43 & 21,43 & 24,49 & 21,88 & 20,54 & 26,86 \\
\hline Wartość max & 23,94 & 33,93 & 24,95 & 32,1 & 24,36 & 25,64 & 22,66 & 21,84 & 27,98 \\
\hline Rozstęp & 1,84 & 1,31 & 1,68 & 1,67 & 2,93 & 1,15 & 0,78 & 1,3 & 1,12 \\
\hline
\end{tabular}

\section{Podsumowanie}

Prowadzone badania przy wykorzystaniu planowania doświadczeń pozwoliły na określenie istotności wpływu 4 czynników na właściwości napoiny przy napawaniu metodą SSA. Do tych czynników należą: prędkość napawania, odbiór ciepła, moc łuku, długość wolnego wylotu elektrody. $Z$ badań i analizy statystycznej wynika, że na wysokość napoiny istotny wpływ ma prędkość napawania, a wraz z jej wzrostem wysokość napoiny będzie malała. Głębokość wtopienia zależy głównie od odbioru ciepła oraz długości wystającego odcinka drutu, które będą ją obniżały. Głębokości wtopienia będą się powiększały przy zwiększaniu mocy łuku elektrycznego. Istotnym parametrem charakteryzującym właściwości warstwy napawanej jest udział materiału rodzimego w napoinie. Wielkość ta zależy przede wszystkim od prędkości napawania, która będzie ją podwyższać, podczas gdy wzrost długości wystającego odcinka drutu będzie ją obniżać.

\section{Literatura}

[1] Klimpel A.: Napawanie i natryskiwanie cieplne - technologie, WNT, Warszawa 2000.

[2] Dziubiński J., Adamiec P.: Napawanie i natryskiwanie wczoraj i dziś, Przegląd Spawalnictwa, Nr 5/1998, s. 6-8.

[3] Nowak A.: Napawanie blach - Materiały XII międzynarodowej konferencji Spawanie w energetyce - Turów 2000", Bogatynia 2000

[4] Dumowic M.: Repair and Maintenance Procedures for Heavy Machinery Components, Welding Innovation, Vol. XX No.1, 2003.

[5] Hartung F.: Technologiczne i metalurgiczne kierunki rozwoju napawania żużlowego, Przegląd Spawalnictwa, Nr 1-2/1996, s. 7-10.

[6] Pierlot C., Pawlowski L., Bigan M., Chagnon P.: Design of experiments in thermal spraying: A review, Surface \& Coatings Technology 202, 2008, s. 4483-4490.

[7] Arcondéguy A., Gasgnier G., Montavon G., Pateyron B., Denoirjean A., Grimaud A., Huguet C.: Effects of spraying parameters onto flame-sprayed glaze coating structures, Surface \& Coatings Technology 202, 2008, s. 4444-4448.

[8] Frydrych D., Rogalski G.: Wpływ warunków spawania podwodnego metodą lokalnej komory suchej na zawartość wodoru dyfundującego w stopiwie, Pzregląd Spawalnictwa, $\mathrm{Nr}$ 11/2009, s. 29-34.

[9] Kukiełka L.: Podstawy badań inżynierskich, PWN, Warszawa 2002. 